\title{
Eribulin Regresses a Cisplatinum-resistant Rare-type Triple-negative Matrix-producing Breast Carcinoma Patient-derived Orthotopic Xenograft Mouse Model
}

\author{
JUN YAMAMOTO ${ }^{1,2,3}$, TAKUYA MURATA ${ }^{4}$, NORIHIKO SUGISAWA ${ }^{1,2}$, TAKASHI HIGUCHI ${ }^{1,2}$, \\ YOSHIHIKO TASHIRO ${ }^{1,2}$, HIROTO NISHINO ${ }^{1,2}$, SACHIKO INUBUSHI ${ }^{1,2}$, YU SUN $^{1,2}$, HYEIN LIM $^{1,2}$, \\ KENTARO MIYAKE ${ }^{3}$, KOICHIRO SHIMOYA ${ }^{5}$, TSUNEHISA NOMURA ${ }^{6}$, \\ JUNICHI KUREBAYASHI ${ }^{6}$, HIROKAZU TANINO ${ }^{7}, \mathrm{CHIHIRO} \mathrm{HOZUMI}^{8}$, \\ MICHAEL BOUVET $^{2}$, SHREE RAM SINGH ${ }^{9}$, ITARU ENDO ${ }^{3}$ and ROBERT M. HOFFMAN ${ }^{1}$ \\ ${ }^{1}$ AntiCancer Inc, San Diego, CA, U.S.A.; \\ ${ }^{2}$ Department of Surgery, University of California, San Diego, CA, U.S.A.; \\ ${ }^{3}$ Department of Gastroenterological Surgery, \\ Yokohama City University Graduate School of Medicine, Yokohama, Japan; \\ ${ }^{4}$ Department of Obstetrics and Gynecology 2, Kawasaki Medical School, Okayama, Japan; \\ ${ }^{5}$ Department of Obstetrics and Gynecology 1, Kawasaki Medical School, Kurashiki, Japan; \\ ${ }^{6}$ Department of Breast and Thyroid Surgery, Kawasaki Medical School, Kurashiki, Japan; \\ ${ }^{7}$ Breast Surgery, Department of Surgery, Kobe University Graduate School of Medicine, Kobe, Japan; \\ ${ }^{8}$ AntiCancer Japan Inc, Narita, Japan; \\ ${ }^{9}$ Basic Research Laboratory, National Cancer Institute, Frederick, MD, U.S.A.
}

\begin{abstract}
Background/Aim: Matrix-producing breast carcinoma $(M P B C)$ is a rare and usually aggressive triplenegative breast cancer (TNBC). In the present report, we determined the drug sensitivity for a triple-negative MPBC using a patient-derived orthotopic xenograft (PDOX) model. Materials and Methods: The PDOX model was established in the left $2^{\text {nd }}$ mammary by surgical orthotopic implantation (SOI). $M P B C$ PDOX models were randomized into 4 groups (6 mice per group) when the tumor volume became $80 \mathrm{~mm}^{3}: \mathrm{Gl}$, control
\end{abstract}

This article is freely accessible online.

Correspondence to: Robert M. Hoffman, Ph.D., AntiCancer Inc, 7917 Ostrow St, San Diego, CA, 92111, U.S.A. Tel: +1 858 6542555, Fax: +1 8582684175, e-mail: all@anticancer.com; Shree Ram Singh, PhD, Basic Research Laboratory, National Cancer Institute, Frederick, MD, 21702, U.S.A. Tel: +1 3018467331, email: singhshr@mail.nih.gov; Itaru Endo, MD, PhD, Department of Gastroenterological Surgery, Yokohama City University Graduate School of Medicine, 3-9 Fukuura, Kanazawa-ku, Yokohama, 2360004, Japan. Tel: +81 457872650, Fax: +81 457829161, e-mail: endoit@yokohama-cu.ac.jp

Key Words: PDOX, patient-derived orthotopic xenograft, TNBC, triple-negative breast cancer, matrix-producing breast carcinoma, eribulin, cisplatinum, tumor regression. group; G2, cisplatinum group [intraperitoneal (i.p.) injection, weekly, for 2 weeks]; G3, paclitaxel group (i.p., weekly, for 2 weeks); G4, eribulin group [intravenous (i.v.) injection, weekly, for 2 weeks]. All mice were sacrificed on day 15. Tumor volume and body weight were measured one time per week. Results: The MPBC PDOX model was resistant to cisplatinum $(p=0.800)$. Paclitaxel suppressed tumor growth compared to the control group $(p=0.009)$. However, only eribulin regressed the tumor ( $p=0.001)$. Conclusion: Eribulin has clinical potential for triple-negative $M P B C$ patients.

Triple-negative breast cancer (TNBC) is a highly aggressive subtype of breast cancer $(1,2)$. TNBC is defined by a lack of estrogen receptor (ER), progesterone receptor (PgR), as well as lack of amplification of human epidermal growth factor receptor 2 (HER-2) $(1,2)$. Approximately $15-20 \%$ of all diagnosed breast cancer cases are $\operatorname{TNBC}(1,2)$. TNBCs often become resistant to standard chemotherapy used against them. Therefore, clinical outcomes for patients with metastatic TNBC (mTNBC) indicate a poor prognosis (3).

Matrix-producing breast carcinoma (MPBC) is a rare and specialized histological type of metaplastic carcinoma (4). MPBC is usually TNBC. MPBC is an invasive breast carcinoma with direct transition to a cartilaginous or osseous matrix having no intervening spindle-cell component $(5,6)$. Therefore, this tumor should be initially treated with chemotherapy. Although 
effective standardized regimens have been established for TNBC of no special histological type (NST TNBC), the efficacy of these treatments for minor histological types are unknown because of their rareness (7). Therefore, identification of effective drugs is urgently needed for MPBC patients.

In the present study, we tested the efficacy of three regimens on a patient-derived orthotopic (PDOX) mouse model of triple-negative MPBC.

\section{Materials and Methods}

Animal studies. In the present study, athymic $n u / n u$ female mice (AntiCancer Inc, San Diego, CA, USA), 4-6 weeks old, were used (8). Procedures for mouse housing, handling, anesthesia, feeding, and humane endpoint criteria have been previously described (911). In order to minimize any suffering of the animals, anesthesia and analgesics were used for all surgical experiments as previously described (9-11). The animal studies were conducted in compliance with an AntiCancer Institutional Animal Care and Use Committee (IACUC)-protocol exclusively approved for this study and in accordance with the principles and procedures outlined in the National Institutes of Health Guide for the Care and Use of Animals under Assurance Number A3873-1 (9-11).

Establishment of the triple-negative MPBC PDOX model. A 43year-old female patient with primary left breast cancer previously received total mastectomy with axillary lymph node dissection at the Kawasaki Medical School Hospital, Japan. The tumor was diagnosed as matrix-producing carcinoma and the results of immunohistostaining were as follows: ER (-), PgR (-), HER2 (-). The patient did not receive any neoadjuvant therapy. Written informed consent was provided by the patient, and the Institutional Ethics Committee of the Kawasaki Medical School approved the PDOX studies. A fresh resected tumor specimen was initially implanted subcutaneously in nude mice for establishment. The established PDOX tumors were cut into $30 \mathrm{~mm}^{3}$ fragments with a surgical orthotopic implantation (SOI) technique (8). A 5-mm skin incision on the left $2^{\text {nd }}$ mammary grand was made under anesthesia. The mammary grand was exposed, and a single fragment was implanted by SOI using 7-0 PDS II (polydioxanone) sutures (Ethicon, Inc., NJ, USA). The wound was closed with 5-0 PDS II sutures (Ethicon, Inc., NJ, USA) (Figure 1) (8).

Treatment protocol for the MPBC PDOX model. Treatment schema is shown in Figure 2. The MPBC PDOX models were randomized into four groups (6 mice in each group) when the tumor volume reached $80 \mathrm{~mm}^{3}$ : G1: untreated group; G2: cisplatinum [intraperitoneal (i.p.) injection, $6 \mathrm{mg} / \mathrm{kg}$, weekly 2 weeks]; G3: paclitaxel (i.p., $25 \mathrm{mg} / \mathrm{kg}$, weekly, 2 weeks); G4: eribulin [intravenous (i.v.) injection, $1 \mathrm{mg} / \mathrm{kg}$, weekly, 2 weeks]. Treatment doses, routes, and schedules were according to our earlier reports (9-11). Tumor volume and body weight was measured once a week using the following formula: tumor volume $(\mathrm{mm})=$ length $(\mathrm{mm}) \times$ width $(\mathrm{mm}) \times$ width $(\mathrm{mm}) \times \frac{1}{2} 2(9-11)$. All mice were sacrificed on day 15 .

Histological examination. Fixation, paraffin-embedding of tissue sections and deparaffinization and rehydration procedures were performed based on our previous reports (9-11). Hematoxylin and eosin (H\&E) staining was performed using a standard protocol.
Histological examination was observed with a BHS system microscope (Olympus Corp., Tokyo, Japan) (9-11).

Statistical analyses. The statistical analyses were performed according to our previous reports (9-11). The one-way ANOVA analysis was performed for comparisons of 4 groups to determine the level of differences followed by Tukey post hoc pairwise tests (9-11). Bar graphs represent the mean, and error bars represent standard deviations. A $p$-value 0.05 or less indicates statistically significant differences.

\section{Results}

Treatment efficacy on the MPBC. The efficacy of cisplatinum, paclitaxel and eribulin was tested using the MPBC PDOX mouse model. Figure 3 shows the tumor volume ratio at day 15 relative to the tumor volume at the beginning of treatment. The MPBC PDOX was resistant to cisplatinum $(p=0.800)$. Paclitaxel suppressed tumor growth significantly compared to the control group $(p=0.009)$. However, only eribulin regressed the MPBC PDOX $(p=0.001)$. The final tumor volume ratios were as follows (day 15 vs. day 0): the untreated control (G1) (4.16 \pm 1.91$)$; cisplatinum-treated (G2) (3.47 \pm 1.26$)$; paclitaxel-treated (G3) (1.46 \pm 1.37$)$; eribulin-treated (G4) $(0.53 \pm 0.14)$. The above results suggest that eribulin was comparatively more efficacious than cisplatinum and paclitaxel in regressing the MPBC PDOX tumor.

Effect of treatment on body weight. We measured the mouse body weight before treatment started and after treatment finished. We found no significant difference in the body weight ratio and body weight loss in any treatment group (Figure 4). These results suggest that the tested treatment doses had no gross side-effects.

Histology of the MPBC PDOX. Figure 5 shows representative photomicrographs of $\mathrm{H} \& \mathrm{E}$-stained sections of a MPBC PDOX tumor in each treatment each group. The control PDOX tumor had viable highly dense cancer cells. PDOX tumors treated with cisplatinum or paclitaxel also contained viable tumor cells, but the cancer-cell densities were lower compared to the control. The PDOX tumors treated with eribulin had the lowest cancer cell density, with necrotic areas and degenerative scars in the stroma, matching the anti-tumor efficacy of the combination.

\section{Discussion}

In the present study, we found that only eribulin, which is one of the drugs recommended for the treatment of recurrent or metastatic TNBC in the National Comprehensive Cancer Network (NCCN) guidelines, regressed tumor growth in a triple-negative MPBC PDOX model. Eribulin mesylate is a synthetic analog of halichondrin $\mathrm{B}$, isolated from the marine 


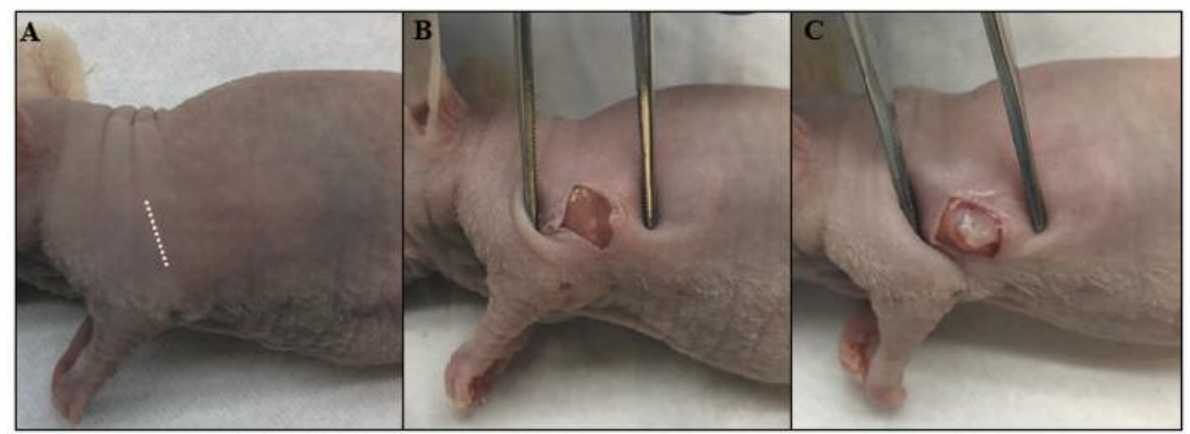

Figure 1. Surgical orthotopic implantation. (A) A 5-mm skin incision was made on the left 2nd mammary grand (white dotted). (B) The mammary grand was exposed. (C) The mammary grand was incised, and a single tumor fragment was implanted at the incised site.

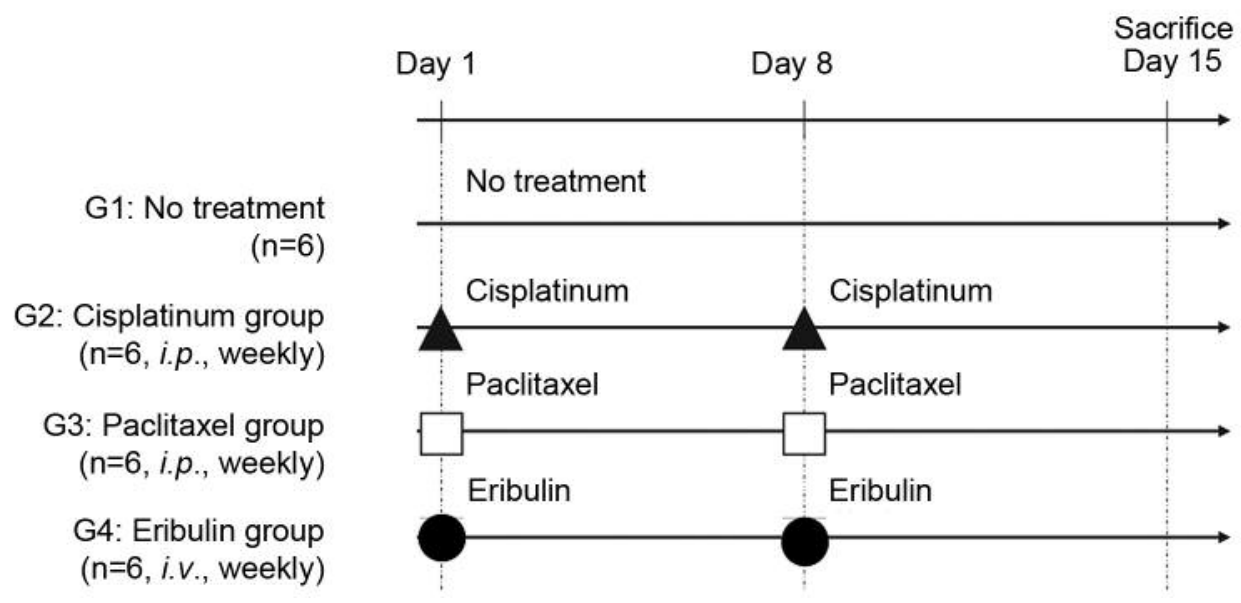

Figure 2. Schema of treatment protocol.

sponge Halichondria okadai (12). Eribulin shows antitumor activity through a tubulin-based anti-mitotic mechanism that resulted in $\mathrm{G}_{2} / \mathrm{M}$ cell-cycle arrest, disruption of mitotic spindles, and apoptotic cell death $(12,13)$. Eribulin inhibits cell growth in a variety of cancer cell lines including breast, colon, prostate, and ovarian cancer (13). In an EMBRACE (Ending Metastatic Breast Cancer for Everyone) clinical trial, eribulin showed overall survival (OS) benefit compared to conventional single-agent chemotherapy in heavily pretreated patients with metastatic breast cancer (14) that resulted in FDA approval in 2011.

TNBCs usually become chemotherapy-resistant upon relapse (3). Therefore, clinical outcome for patients with metastatic TNBC (mTNBC) is needed specifically with and overall survival (OS) of approximately 13-16 months, that is mostly due to lack of effective targeted therapy (3).

MPBC is a rare tumor with few reported studies, which included a small number of cases (15). Kusafuka et al. reported the prevalence of MPBCs among all invasive breast cancer cases at $0.2 \%(6)$. MPBC is usually TNBC and has higher proliferative activity than NST TNBCs (36\%), suggesting that MPBCs are a biologically aggressive subgroup of TNBC $(4,5,7)$.

We developed a PDOX mouse model for breast cancer in 1993 (8) and all other major cancers (9, 16-20). We demonstrated that the PDOX model is more patient-like than that of subcutaneous patient-derived xenograft (PDX) models (16). Previously we have demonstrated that the PDOX model retains the histopathological/molecular characteristics of the original tumor when transplanted in mice (16-20). PDOX models provide a unique opportunity to derive precise and personalized treatment choices for MPBC and other cancer patients.

Eribulin regressed cisplatinum-resistant triple-negative MPBC in a PDOX model without apparent side-effects. The MPBC PDOX model should enable precise, individualized, improved therapy for patients with this recalcitrant disease. In this case, the PDOX model identified eribulin as particularly effective and the results suggest that the patient should be treated with this drug. 


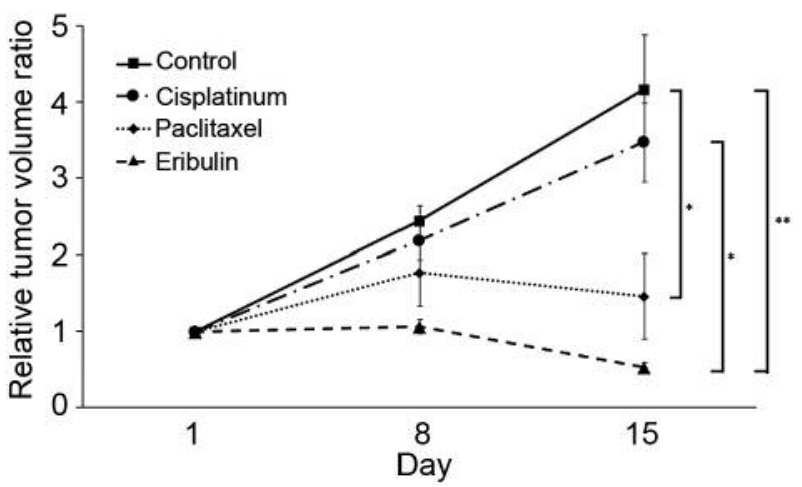

Figure 3. Quantitative efficacy of chemotherapy on the MPBC PDOX tumor. A. Relative tumor volume (tumor volume ratio is the tumor volume at any time point relative to the tumor volume at the beginning of the treatment period). Line graphs shows the relative tumor volume. Pacltaxel suppressed tumor growth significantly compared to control group $(p=0.009)$. Eribulin significantly regressed tumor growth $(p=0.001) .{ }^{*} p<0.01 .{ }^{* *} p=0.001$. Error bars: \pm SEM.

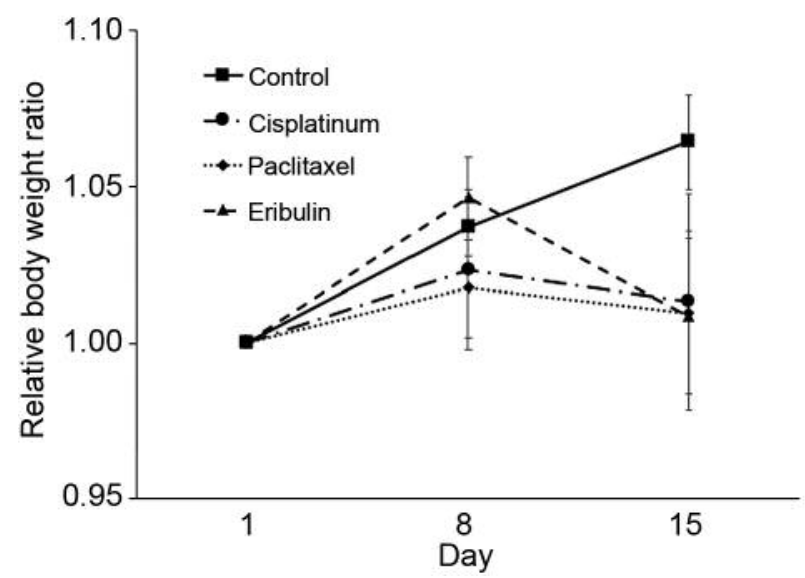

Figure 4. Relative body weight. Line graphs illustrate relative body weight in each group on each day. Error bars: \pm SEM.
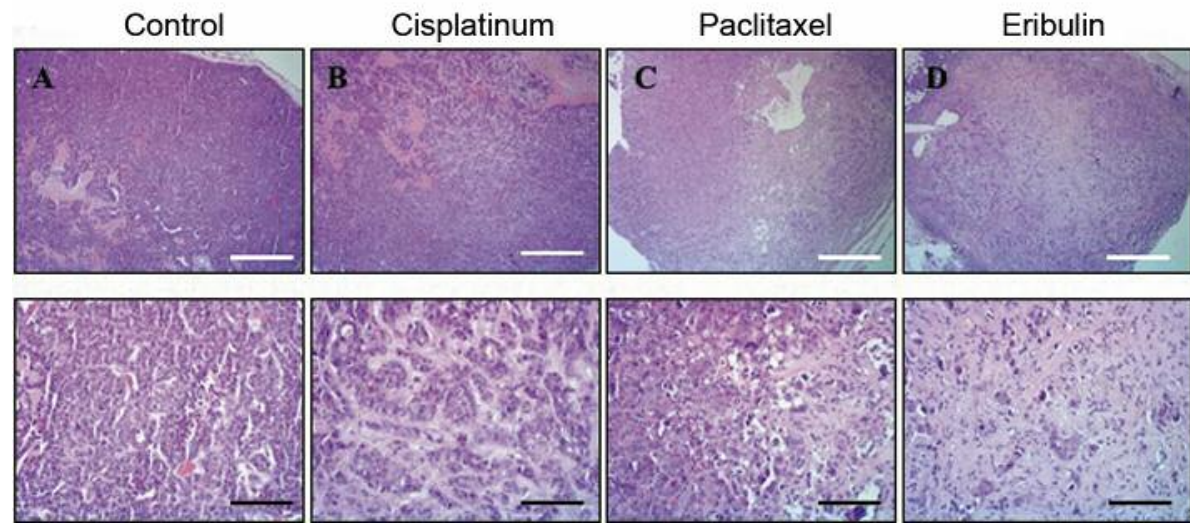

Figure 5. Tumor histology. (A) Hematoxylin and eosin (H\&E) staining of the untreated MPBC PDOX tumor. (B) H\&E staining of the MPBC PDOX tumor treated with cisplatinum. (C) $H \& E$ staining of the paclitaxel-treated MPBC PDOX tumor. $(D) H \& E$ staining of the eribulin-treated MPBC

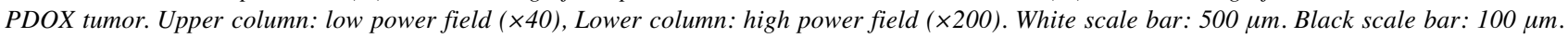

\section{Conflicts of Interest}

AntiCancer Inc. uses PDOX models for contract research. JY, TM, NS, TH, YT, HN, SI, YS, HL, KM and RMH are or were unsalaried associates of AntiCancer Inc. There are no other competing financial interests.

\section{Authors' Contributions}

J.Y. and R.M.H designed and performed experiments, analyzed data and wrote the paper; T.M. provided tumor; C.H. established the tumor in nude mice; N.S., T.H., Y.T., S.I, Y.S., H.L., C.H., K.M., and M.B. gave technical support and conceptual advice. Writing, review, and/or revision of the manuscript: J.Y., R.M.H, I.E., and S.R.S.

\section{Acknowledgements}

This paper is dedicated to the memory of A. R. Moossa, M.D., Sun Lee, M.D., Professor Li Jiaxi, and Masaki Kitajima, MD.

\section{Funding}

This work was supported in part by a Yokohama City University research grant "KAMOME Project", which had no role in the design, execution, interpretation, or writing of the study. 


\section{References}

1 SEER Cancer Statistics Review, 1975-2014. National Cancer Institute, 2017.

2 Carey LA, Perou CM, Livasy CA, Dressler LG, Cowan D, Conway K, Karaca G, Troester MA, Tse CK, Edmiston S, Deming SL, Geradts J, Cheang MC, Nielsen TO, Moorman PG, Earp HS and Millikan RC: Race, Breast cancer subtypes, and survival in the Carolina breast cancer study. JAMA 295(21): 2492-502, 2006. PMID: 16757721. DOI: 10.1001/jama.295.21.2492

3 Liedtke C, Mazouni C, Hess KR, André F, Tordai A, Mejia JA, Symmans WF, Gonzalez-Angulo AM, Hennessy B, Green M, Cristofanilli M, Hortobagyi GN and Pusztai L: Response to neoadjuvant therapy and long-term survival in patients with triple-negative breast cancer. J Clin Oncol 26(8): 1275-1281, 2008. PMID: 18250347. DOI: 10.1200/JCO.2007.14.4147

4 Wargotz ES and Norris HJ: Metaplastic carcinomas of the breast. I. Matrix-producing carcinoma. Human Pathol 20(7): 628-635, 1989. PMID: 2544506. DOI: 10.1016/0046-8177(89)90149-4

5 Gibson GR, Qian D, Ku JK and Lai LL: Metaplastic breast cancer: clinical features and outcomes. Am Surg 71(9): 725-730, 2005. PMID: 16468506 .

6 Kusafuka K, Muramatsu K, Kasami M, Kuriki K, Hirobe K, Hayashi I, Watanabe H, Hiraki Y, Shukunami C, Mochizuki T and Kameya T: Cartilaginous features in matrix-producing carcinoma of the breast: four cases report with histochemical and immunohistochemical analysis of matrix molecules. Modern Pathol 21(10): 1282-1292, 2008. PMID: 18622387. DOI: 10.1038/modpathol.2008.120

7 Shimada K, Ishikawa T, Yamada A, Sugae S, Narui K, Shimizu $\mathrm{D}$, Chishima T and Endo I: Matrix-producing carcinoma as an aggressive triple-negative breast cancer: clinicopathological features and response to neoadjuvant chemotherapy. Anticancer Res 39(7): 3863-3869, 2019; PMID: 31262914. DOI: 10.21873/ anticanres. 13536

8 Fu X, Le P and Hoffman RM: A metastatic orthotopic-transplant nude-mouse model of human patient breast cancer. Anticancer Res 13(4): 901-904, 1993. PMID: 8352558.

9 Zhu G, Zhao M, Han Q, Tan Y, Sun YU, Bouvet M, Singh SR, Ye J and Hoffman RM: Pazopanib inhibits tumor growth, lymph-node metastasis and lymphangiogenesis of an orthotopic mouse of colorectal cancer. Cancer Genomics Proteomics 17(2): 131-139, 2020. PMID: 32108035. DOI: $10.21873 / \mathrm{cgp} .20173$

10 Kiyuna T, Tome Y, Miyake K, Murakami T, Oshiro H, Igarashi K, Kawaguchi K, Hsu J, Singh M, Li Y, Nelson S, Bouvet M, Singh SR, Kanaya F and Hoffman RM: Eribulin suppressed cisplatinum- and doxorubicin-resistant recurrent lung metastatic osteosarcoma in a patient-derived orthotopic xenograft mouse model. Anticancer Res 39(9): 4775-4779, 2019. PMID: 31519578. DOI: 10.21873 /anticanres.13661

11 Higuchi T, Yamamoto J, Sugisawa N, Tashiro Y, Nishino H, Yamamoto N, Hayashi K, Kimura H, Miwa S, Igarashi K, Bouvet M, Singh SR, Tsuchiya H and Hoffman RM: PPAR $\gamma$ agonist pioglitazone in combination with cisplatinum arrests a chemotherapy-resistan osteosarcoma PDOX Model. Cancer Genomics Proteomics 17(1): 35-40, 2020. PMID: 31882549. DOI: $10.21873 / \mathrm{cgp} .20165$

12 Uemura D, Takahashi K, Yamamoto T, Katayama C, Tanaka J, Okumura $\mathrm{Y}$ and Hirata $\mathrm{Y}$ : Norhalichondrin A: an antitumor polyether macrolide from a marine sponge. J Amer Chem Soc 107(16): 4796-4798, 1985. DOI: 10.1021/ja00302a042

13 Kuznetsov G, Towle MJ, Cheng H, Kawamura T, TenDyke K, Liu D, Kishi Y, Yu MJ and Littlefield BA: Induction of morphological and biochemical apoptosis following prolonged mitotic blockage by halichondrin B macrocyclic ketone analog E7389. Cancer Res 64(16): 5760-5766, 2004. PMID: 15313917. DOI: $10.1158 / 0008-5472 . C A N-04-1169$

14 Cortes J, O'Shaughnessy J, Loesch D, Blum JL, Vahdat LT, Petrakova K, Chollet P, Manikas A, Diéras V, Delozier T, Vladimirov V, Cardoso F, Koh H, Bougnoux P, Dutcus CE, Seegobin S, Mir D, Meneses N, Wanders J, Twelves C; EMBRACE (Eisai Metastatic Breast Cancer Study Assessing Physician's Choice Versus E7389) investigators: Eribulin monotherapy versus treatment of physician's choice in patients with metastatic breast cancer (EMBRACE): a phase 3 open-label randomised study. Lancet 377(9769): 914-923, 2011. PMID: 21376385. DOI: 10.1016/S0140-6736(11)60070-6

15 Ayar S, Dyess DL and Carter E: Matrix-producing carcinoma: a rare variant of metaplastic breast carcinoma with heterologous elements. Breast J 16(4): 420-423, 2010. PMID: 20522099. DOI: 10.1111/j.1524-4741.2010.00925.x

16 Hiroshima Y, Maawy A, Zhang Y, Zhang N, Murakami T, Chishima T, Tanaka K, Ichikawa Y, Bouvet M, Endo I and Hoffman RM: Patient-derived mouse models of cancer need to be orthotopic in order to evaluate targeted anti-metastatic therapy. Oncotarget 7(44): 71696-71702, 2016. PMID: 27765934. DOI: 10.18632 /oncotarget.12322

17 Miyake K, Kawaguchi K, Kiyuna T, Miyake M, Igarashi K, Zhang Z, Murakami T, Li Y, Nelson SD, Elliott I, Russell T, Singh A, Hiroshima Y, Momiyama M, Matsuyama R, Chishima T, Endo I, Eilber FC and Hoffman RM: Regorafenib regresses an imatinibresistant recurrent gastrointestinal stromal tumor (GIST) with a mutation in exons 11 and 17 of c-kit in a patient-derived orthotopic xenograft (PDOX) nude mouse model. Cell Cycle 17(6): 722-727, 2018. PMID: 29334307. DOI: 10.1080/15384101.2017.1423223

18 Miyake K, Higuchi T, Oshiro H, Zhang Z, Sugisawa N, Park JH, Razmjooei S, Katsuya Y, Barangi M, Li Y, Nelson SD, Murakami T, Homma Y, Hiroshima Y, Matsuyama R, Bouvet M, Chawla SP, Singh SR, Endo I and Hoffman RM: The combination of gemcitabine and docetaxel arrests a doxorubicinresistant dedifferentiated liposarcoma in a patient-derived orthotopic xenograft model. Biomed Pharmacother 117: 109093, 2019. PMID: 31200257. DOI: 10.1016/j.biopha.2019.109093

19 Hoffman RM: Patient-derived orthotopic xenografts: better mimic of metastasis than subcutaneous xenografts. Nat Rev Cancer 15(8): 451-452, 2015. PMID: 26422835. DOI: 10.1038/nrc3972

20 Hoffman RM: Orthotopic is orthodox: why are orthotopictransplant metastatic models different from all other models? J Cell Biochem 56(1): 1-3, 1994. PMID: 7806583. DOI: $10.1002 / \mathrm{jcb} .240560102$
Received March 6, 2020

Revised March 18, 2020

Accepted March 19, 2020 